\title{
Linear extension, skeletal density, and calcification rates of the blue coral Heliopora coerulea
}

\author{
Travis A. Courtney ${ }^{1}$ (1) $\cdot$ James R. Guest $^{2}$ (D) Alasdair J. Edwards $^{2}$ (D) \\ Romeo M. Dizon ${ }^{3}$
}

Received: 25 January 2021 / Accepted: 10 June 2021 / Published online: 29 July 2021

(C) The Author(s) 2021

\begin{abstract}
The brooding reef-building octocoral Heliopora is widespread on Indo-West Pacific reefs and appears to be relatively resistant to thermal stress, which may enable it to persist locally while scleractinians diminish under Anthropocene conditions. However, basic physiological measurements of "blue corals" are lacking and prevent their inclusion in trait-based studies. We address this by quantifying rates (mean $\pm \mathrm{SE}$ ) of linear extension $\left(0.86 \pm 0.05 \mathrm{~cm} \mathrm{yr}^{-1}\right)$ and skeletal density $\left(2.01 \pm 0.06 \mathrm{~g} \mathrm{~cm}^{-3}\right)$ to estimate calcification rates $\left(0.87 \pm 0.08 \mathrm{~g} \mathrm{~cm}^{-2} \mathrm{yr}^{-1}\right)$ for the small branching/columnar morphology of Heliopora coerulea. We postulate that $H$. coerulea may become an increasingly important reef-builder under ocean warming due to its relative resistance to thermal stress and high skeletal density that make colonies less vulnerable to storm damage under ocean acidification. Moreover, Heliopora corals are likely dispersal limited suggesting they may be an underappreciated genus for restoration of stress-tolerant reefbuilding capacity on degraded reefs.
\end{abstract}

Travis A. Courtney

traviscourtney@gmail.com

$\triangle$ James R. Guest

jrguest@gmail.com

1 Scripps Institution of Oceanography, University of California, La Jolla, San Diego, CA, USA

2 School of Natural and Environmental Sciences, Newcastle University, Newcastle upon Tyne, UK

3 Department of Biology, University of the Philippines Baguio, Baguio City, Philippines
Keywords Extension - Skeletal density $\cdot$ Calcification rate $\cdot$ Blue coral $\cdot$ Octocoral $\cdot$ Ocean warming Ocean acidification $\cdot$ Coral reef restoration

\section{Introduction}

Calcium carbonate production represents one of the core functions of coral reef ecosystems (Brandl et al. 2019) and can be approximated from estimates of benthic cover and taxa-specific calcification rates as part of census-based coral reef carbonate production budgets (Perry et al. 2012). While notable efforts have advanced estimates of carbonate production states through the aggregation of publicly accessible coral linear extension, skeletal density, and calcification rate data (e.g., Perry et al. 2012; Madin et al. 2016), basic physiology measurements of the reef-building octocoral genus Heliopora are largely absent from these databases. To the best of our knowledge, these are limited to rates of lateral overgrowth of $2.1 \pm 0.9 \mathrm{~cm} \mathrm{yr}^{-1}$ for $H$. coerulea over Porites spp. corals reported by Guzman et al. (2019) and a solitary $H$. coerulea calcification rate estimate of $0.48 \mathrm{~g} \mathrm{~cm}^{-2} \mathrm{yr}^{-1}$ (by Planck et al. 1988 in Ryan et al. 2019) in the scientific literature.

Widely distributed across the Indo-Pacific, Heliopora corals are distinct in that they represent the only known genus of hermatypic octocorals (Zann and Bolton 1985). Often termed "blue corals" owing to the incorporation of iron salts into their skeletal aragonite, Heliopora are generally typified by their iconic blue skeletons (Hill 1960; Richards et al. 2018). Heliopora coerulea was considered the only extant species, but recent genetic evidence has suggested cryptic speciation within $H$. coerulea between small and flat branching morphologies (Yasuda et al. 2014) that have asynchronous reproductive timing (Villanueva 
2016). Heliopora hiberniana was also recently described in north Western Australia (Richards et al. 2018). Interestingly, Heliopora appears to have higher optimal temperature ranges compared to many scleractinian corals as evidenced by apparent range retractions during periods of cooling (Zann and Bolton 1985), high degree of bleaching resistance and resilience during recent thermal stress events (Kayanne et al. 2002; Donner et al. 2010; Phongsuwan and Changsang 2012; Harii et al. 2014; Richards et al. 2018; Guzman et al. 2019; Ryan et al. 2019), apparent increasing competitive advantage in warmer waters (Atrigenio et al. 2020), and growth rates that increase with seawater temperatures up to at least $31^{\circ} \mathrm{C}$ (Guzman et al. 2019). $H$. coerulea also contributed to the maintenance of positive coral reef carbonate production states following a coral bleaching event (Ryan et al. 2019), providing further evidence that $H$. coerulea may become increasingly important reef-builders under ongoing ocean warming.

Owing to the absence of basic physiology data for $\mathrm{He}$ liopora corals, it remains unclear how the increasing relative abundance of Heliopora corals may impact coral reef geo-ecological functions under ongoing ocean warming and acidification. In this study, we quantify linear extension and skeletal density to estimate morphology-specific calcification rates to fill these gaps in the trait-based coral literature and speculate as to the role of Heliopora coerulea as an emerging reef-builder and potential restoration target in the Anthropocene.

\section{Methods}

\section{Linear extension}

Large and small Heliopora coerulea fragments $(n=100)$ of mean $( \pm \mathrm{SE})$ initial planar area of $22.3 \pm 1.5 \mathrm{~cm}^{2}$ $\left(n=50\right.$ large fragments) and $5.2 \pm 0.2 \mathrm{~cm}^{2}(n=50$ small fragments) were used to estimate linear extension rates from repeated measures of height through time. All

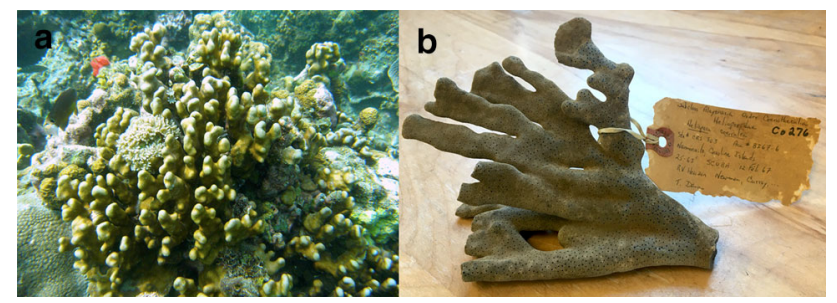

Fig. 1 a Heliopora coerulea from Bolinao, Philippines showing the typical light brown coloration of living colonies. Photograph by JR Guest. b Heliopora coerulea skeletal specimen from the Scripps Institution of Oceanography Benthic Invertebrate Collections (SIOBIC Co276) showing the iconic blue skeletal coloration. Photograph by TA Courtney fragments represented the small branching/columnar morphology sensu Yasuda et al. (2014) and Villanueva (2016) (Fig. 1a). Fragments were sourced from 25 independent colonies (four fragments per colony) and epoxied (Pioneer Epoxyclay Aqua ${ }^{\mathrm{TM}}$ ) onto replicate calcium carbonate substrates (locally aquacultured Tridacna gigas shells) mounted on plastic mesh frames between mid-December 2005 and mid-January 2006 in five replicate plots at 2.9-3.4 m depth within the lagoon north of Silaqui Island, Philippines $\left(16^{\circ} 26^{\prime} 22.0^{\prime \prime} \mathrm{N} \quad 119^{\circ} 56^{\prime} 37.8^{\prime \prime} \mathrm{E}\right)$. All linear extension data presented here were collected as part of a larger experiment to examine coral growth and survival rates (e.g., see Guest et al. (2011) for further details on study design and photographs of outplanted corals). Linear extension was determined from repeated caliper (precision $=0.1 \mathrm{~mm}$ ) measurements of fragment height on six occasions in February, May, and October 2006, April and September 2007, and finally in May 2008. Over the 2.25 years of the study, none of the 100 fragments suffered mortality, but two were either broken or became unattached, so only prior growth was recorded. Linear extension $\left(\mathrm{cm} \mathrm{yr}^{-1}\right)$ was estimated from the least squares regression line slope of height $(\mathrm{cm})$ vs. time $(\mathrm{yr})$ from each survey for each fragment to make use of the six repeated height measurements for each fragment and minimize effects of individual measurement error.

\section{Skeletal density}

In the absence of direct, contemporaneous skeletal density measurements on the outplanted Heliopora coerulea fragments, we used three specimens collected from the Federated States of Micronesia in 1967 and preserved in the Scripps Institution of Oceanography Benthic Invertebrate Collection (i.e., SIO-BIC Co151, Co276, Co277) (Fig. 1b) to quantify $H$. coerulea skeletal density and estimate calcification rates. Archimedes' principle was used to determine bulk skeletal densities $\left(\mathrm{g} \mathrm{cm}^{-3}\right)$ from the mass of skeletal material ( $\mathrm{g}$ ) divided by the volume of water displaced $\left(\mathrm{cm}^{3}\right)$ (Jokiel et al. 1978; Morgan and Kench 2012). The mass of each skeletal fragment was determined via direct measurement of the dry skeleton. The volume of displaced water for each respective skeletal fragment $\left(\mathrm{cm}^{3}\right)$ was determined via the seawater equation of state (i.e., $R$ package seacarb; Gattuso et al. 2020) using the mass (g), temperature $\left({ }^{\circ} \mathrm{C}\right)$, and salinity (ppt) of the displaced water upon submergence of the skeleton in deionized water. We assumed that $H$. coerulea skeletal voids were small and poorly connected with minimal influence on bulk skeletal density measurements and therefore did not dip the specimens in paraffin wax prior to displacement in water (Bucher et al. 1998). Mass was determined via an Ohaus Scout SPX422 balance (precision $= \pm 0.01 \mathrm{~g}$ ) that was 
verified for accuracy with a calibration weight prior to measurements. A YSI Pro 2030 was used to measure temperature (precision $= \pm 0.3{ }^{\circ} \mathrm{C}$ ) and salinity (precision $= \pm 0.1 \mathrm{ppt}$ ). Skeletal densities were compared to recent bulk skeletal densities of Indian Ocean scleractinians determined using analogous methods (Morgan and Kench 2012).

\section{Calcification rates}

The scaling of coral calcification rates represents a considerable ongoing challenge owing to the three-dimensional structural complexity of coral skeletons, so we used methods analogous to Morgan and Kench (2012) to directly compare our estimated calcification rates to those of that study. The small branching/columnar $H$. coerulea specimens in this study most closely approximated the Pocillopora meandrina submassive morphology from Morgan and Kench (2012), so we used the adjustment coefficient of 0.5 for that species to account for the open space in our estimates of $H$. coerulea. We therefore estimated mean ( $\pm \mathrm{SE}$ ) H. coerulea calcification rates from the product of linear extension, skeletal density, and the 0.5 adjustment coefficient following Morgan and Kench (2012).

\section{Results and discussion}

\section{Linear extension}

Mean ( \pm SE) linear extension did not differ significantly between the large $\left(0.88 \pm 0.08 \mathrm{~cm} \mathrm{yr}^{-1}\right)$ and small $\left(0.83 \pm 0.06 \mathrm{~cm} \mathrm{yr}^{-1}\right)$ fragments (two-sample $t$-test, $p=0.531)$, so we calculated the mean $( \pm \mathrm{SE})$ linear extension rate for all $H$. coerulea fragments $(n=100)$. This rate $\left(0.86 \pm 0.05 \mathrm{~cm} \mathrm{yr}^{-1}\right)$ was lower than the extension rates of $2.1 \pm 0.9 \mathrm{~cm} \mathrm{yr}^{-1}$ reported for $H$. coerulea laterally overgrowing massive Porites spp. by Guzman et al. (2019). It is unlikely that environmental and/ or genotypic controls caused these differences in growth rates (Pratchett et al. 2015) as the data were collected from approximately the same study locations (Bolinao, Philippines). We posit that these differences were most likely due to measurements of linear extension of skeletal branches (this study) versus lateral extension of a thin veneer of encrusted skeletal material over massive Porites spp. (Guzman et al. 2019). Our mean ( \pm SE) extension rate of $0.86 \pm 0.05 \mathrm{~cm} \mathrm{yr}^{-1}$ for $H$. coerulea is less than the branching, corymbose, digitate, and massive scleractinians, similar to submassive scleractinians, and greater than mushroom and encrusting scleractinians observed by Morgan and Kench (2012) (Fig. 2).

\section{Skeletal density}

Mean ( \pm SE) skeletal densities for Heliopora coerulea of $2.01 \pm 0.06 \mathrm{~g} \mathrm{~cm}^{-3}$ in this study were higher than any of the scleractinian skeletal densities observed by Morgan and Kench (2012) (Fig. 2). Ocean acidification (OA) threatens to reduce scleractinian coral skeletal density, which could lead to increased breakage of coral skeletal materials and decreased reef-building capacity (Hoegh-Guldberg et al. 2007). Whether distinct differences in the skeletal morphology of $H$. coerulea may confer some resilience to OA by these reef-building octocorals remains to be tested (Atrigenio et al. 2020). Regardless, the comparatively higher skeletal density of $H$. coerulea relative to its scleractinian morphological counterparts suggests that $H$. coerulea skeletons could be more resistant to such physical breakage under OA. However, we cannot rule out the possibilities that slight differences in methodologies (i.e., omission of paraffin wax dip in this study) or that Heliopora skeletal densities were indeed higher in 1967 and have since decreased under ongoing environmental change, so further research remains necessary to test any hypothesized resiliency of Heliopora corals and their skeletal components to environmental change.

\section{Calcification rates}

Mean ( $\pm \mathrm{SE}$ ) estimated calcification rates for Heliopora coerulea were $0.87 \pm 0.08 \mathrm{~g} \mathrm{~cm}^{-2} \mathrm{yr}^{-1}$ for the small branching/columnar morphology investigated in this study (Fig. 2). This rate is greater than the solitary calcification rate estimate of $0.48 \mathrm{~g} \mathrm{~cm}^{-2} \mathrm{yr}^{-1}$ for $H$. coerulea by Planck et al. (1988) in Ryan et al. (2019), which may in part be due to differences in methodologies and/or morphologies between the previous measurement and this study. Notably, H. coerulea calcification rates are less than those for branching, corymbose, digitate, and massive scleractinians, in general agreement with rates for submassive morphologies, and are greater than mushroom and encrusting scleractinian calcification rates by Morgan and Kench (2012) (Fig. 2). While variability in calcification rates through space and time (Pratchett et al. 2015) confound a more direct comparison of calcification rates between taxa, these estimates nonetheless suggest that offsetting slower linear extension and higher density skeletal material of $H$. coerulea generate carbonate production rates similar to other reef-building scleractinian taxa. 

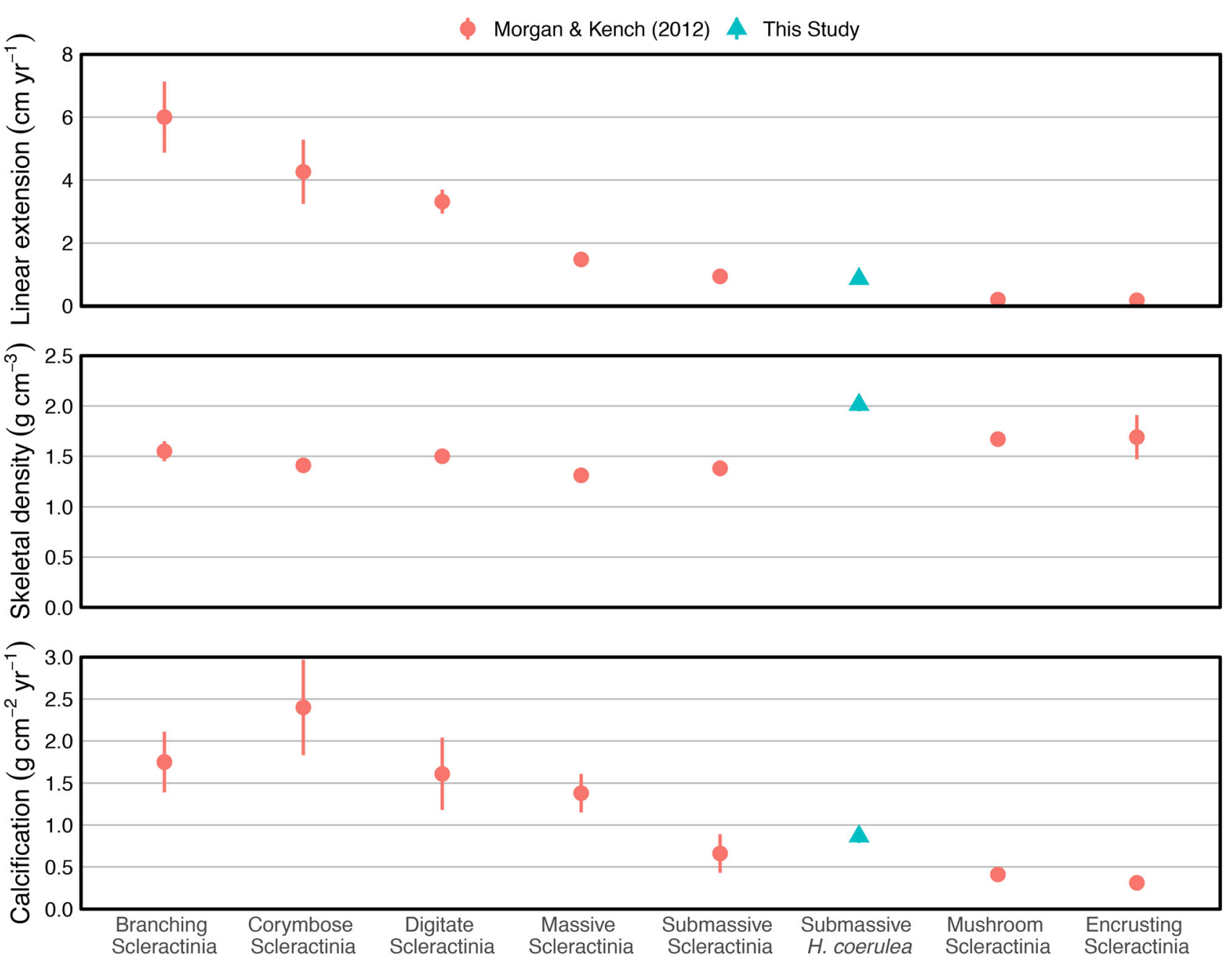

Fig. 2 Mean ( \pm standard error) linear extension, skeletal density, and calcification rates for Heliopora coerulea from this study are plotted relative to Indian Ocean scleractinian corals from Morgan and Kench (2012)

\section{Implications for reef building and restoration in the Anthropocene}

Owing to their higher degree of resilience to thermal stress anomalies and apparent increasing ability to outcompete scleractinians under ocean warming, Heliopora corals may become increasingly abundant reef-builders (Kayanne et al. 2002; Donner et al. 2010; Phongsuwan and Changsang 2012; Harii et al. 2014; Richards et al. 2018; Guzman et al. 2019; Ryan et al. 2019; Atrigenio et al., 2020). Interestingly, Heliopora tends to form dense aggregations and may be dispersal limited owing to benthic planulae that settle near the parent colony (Zann and Bolton 1985; Harii et al. 2002). We posit that outplanting of stress-tolerant reefbuilding Heliopora corals to degraded reef systems within its current geographic range may enable restoration of structural complexity and calcium carbonate production to select reefs. However, such restoration strategies could inhibit growth and/or recruitment by scleractinian corals (Atrigenio et al. 2017; Guzman et al. 2019; Atrigenio et al. 2020) and should therefore critically evaluate any potential resulting consequences as part of a broader decision-making framework (National Academies of Sciences 2019). We conclude that Heliopora corals warrant further research as potentially emerging reef-builders and target taxa for restoration and adaptation efforts in the Anthropocene.

Supplementary InformationThe online version contains supplementary material available at https://doi.org/10.1007/s00338021-02137-3.

Acknowledgements We thank Dr. Charlotte Seid for loaning $\mathrm{He}$ liopora coerulea specimens from the Benthic Invertebrate Collection of Scripps Institution of Oceanography and three anonymous reviewers for improving this manuscript with their constructive comments. TAC was supported by funding from the National Oceanographic and Atmospheric Administration Ocean Acidification Program. All linear extension and skeletal density data are publicly accessible via the electronic supplementary materials. On behalf of all 
authors, the corresponding author states that there is no conflict of interest.

Open Access This article is licensed under a Creative Commons Attribution 4.0 International License, which permits use, sharing, adaptation, distribution and reproduction in any medium or format, as long as you give appropriate credit to the original author(s) and the source, provide a link to the Creative Commons licence, and indicate if changes were made. The images or other third party material in this article are included in the article's Creative Commons licence, unless indicated otherwise in a credit line to the material. If material is not included in the article's Creative Commons licence and your intended use is not permitted by statutory regulation or exceeds the permitted use, you will need to obtain permission directly from the copyright holder. To view a copy of this licence, visit http://creativecommons. org/licenses/by/4.0/.

\section{References}

Atrigenio M, Aliño P, Conaco C (2017) Influence of the Blue Coral Heliopora coerulea on Scleractinian Coral Larval Recruitment. Journal of Marine Biology 2017:6015143

Atrigenio M, Conaco C, Guzman C, Yap HT, Aliño PM (2020) Distribution and abundance of Heliopora coerulea (Cnidaria: Coenothecalia) and notes on its aggressive behavior against scleractinian corals: Temperature mediated? Regional Studies in Marine Science 40:101502

Brandl SJ, Rasher DB, Côté IM, Casey JM, Darling ES, Lefcheck JS, Duffy JE (2019) Coral reef ecosystem functioning: eight core processes and the role of biodiversity. Frontiers in Ecology and the Environment 17:445-454

Bucher DJ, Harriott VJ, Roberts LG (1998) Skeletal micro-density, porosity, and bulk density of acroporid corals. Journal of Experimental Marine Biology and Ecology 228:117-136

Donner SD, Kirata T, Vieux C (2010) Recovery from the 2004 coral bleaching event in the Gilbert Islands, Kiribati. Atoll Research Bulletin 587:1-25

Gattuso J-P, Epitalon J-M, Lavigne H, Orr J (2020) seacarb: Seawater Carbonate Chemistry. R package version $3.2 .13 \mathrm{https}: / / C R A N$. R-project.org/package $=$ seacarb.

Guest JR, Dizon RM, Edwards AJ, Franco C, Gomez ED (2011) How Quickly do Fragments of Coral "Self-Attach" after Transplantation? Restoration Ecology 19:234-242

Guzman C, Atrigenio M, Shinzato C, Aliño P, Conaco C (2019) Warm seawater temperature promotes substrate colonization by the blue coral Heliopora coerulea. PeerJ 7:e7785

Harii S, Kayanne H, Takigawa H, Hayashibara T, Yamamoto M (2002) Larval survivorship, competency periods and settlement of two brooding corals, Heliopora coerulea and Pocillopora damicornis. Marine Biology 141:39-46

Harii S, Hongo C, Ishihara M, Ide Y, Kayanne H (2014) Impacts of multiple disturbances on coral communities at Ishigaki Island, Okinawa, Japan, during a 15 year survey. Marine Ecology Progress Series 509:171-180

Hill D (1960) Possible intermediates between Alcyonaria, Tabulata and Rugosa, and Rugosa and Hexacorallia. Int Geol Cong 22:51-58

Hoegh-Guldberg O, Mumby PJ, Hooten A, Steneck RS, Greenfield P, Gomez E, Harvell CD, Sale PF, Edwards AJ, Caldeira K,
Knowlton N, Eakin CM, Iglesias-Prieto R, Muthiga N, Bradbury RH, Dubi A, Hatziolos ME (2007) Coral reefs under rapid climate change and ocean acidification. Science 318:1737-1742

Jokiel PL, Maragos JE, Franzisket L (1978) Coral growth: buoyant weight technique. In: Stoddardt D, Johannes R (eds) Coral reefs: research methods. UNESCO, Paris, pp 529-541

Kayanne H, Harii S, Ide Y, Akimoto F (2002) Recovery of coral populations after the 1998 bleaching on Shiraho Reef, in the southern Ryukyus, NW Pacific. Marine Ecology Progress Series 239:93-103

Madin JS, Hoogenboom MO, Connolly SR, Darling ES, Falster DS, Huang D, Keith SA, Mizerek T, Pandolfi JM, Putnam HM, Baird AH (2016) A Trait-Based Approach to Advance Coral Reef Science. Trends in Ecology and Evolution 31:419-428

Morgan KM, Kench PS (2012) Skeletal extension and calcification of reef-building corals in the central Indian Ocean. Marine Environmental Research 81:78-82

National Academies of Sciences (2019) A Decision Framework for Interventions to Increase the Persistence and Resilience of Coral Reefs. Washington, DC: National Academies Press.

Perry CT, Edinger EN, Kench PS, Murphy GN, Smithers SG, Steneck RS, Mumby PJ (2012) Estimating rates of biologically driven coral reef framework production and erosion: A new censusbased carbonate budget methodology and applications to the reefs of Bonaire. Coral Reefs 31:853-868

Phongsuwan N, Changsang H (2012) Repeated Coral Bleaching in the Andaman Sea, Thailand, During the Last Two Decades. Phuket Marine Biological Center Research Bulletin 71:19-41

Planck RJ, MicAllister DE, McAllister AT (1988) Shiraho coral reef and the proposed new Ishigaki Island Airport, Japan. International Union for Conservation of Nature and Natural Resources, Morgas Switzerland

Pratchett MS, Anderson KD, Hoogenboom MO, Widman E, Baird AH, Pandolfi JM, Edmunds PJ, Lough JM (2015) Spatial, temporal and taxonomic variation in coral growth - implications for the structure and function of coral reef ecosystems. Oceanography and Marine Biology: An Annual Review 53:215-296

Richards ZT, Yasuda N, Kikuchi T, Foster T, Mitsuyuki C, Stat M, Suyama Y, Wilson NG (2018) Integrated evidence reveals a new species in the ancient blue coral genus Heliopora (Octocorallia). Scientific Reports 8:15875

Ryan EJ, Hanmer K, Kench PS (2019) Massive corals maintain a positive carbonate budget of a Maldivian upper reef platform despite major bleaching event. Scientific Reports 9:6515

Villanueva RD (2016) Cryptic speciation in the stony octocoral Heliopora coerulea: temporal reproductive isolation between two growth forms. Mar Biodiv 46:503-507

Yasuda N, Taquet C, Nagai S, Fortes M, Fan T-Y, Phongsuwan N, Nadaoka K (2014) Genetic structure and cryptic speciation in the threatened reef-building coral Heliopora coerulea along Kuroshio Current. Bulletin of Marine Science 90:233-255

Zann LP, Bolton L (1985) The distribution, abundance and ecology of the blue coral Heliopora coerulea (Pallas) in the Pacific. Coral Reefs 4:125-134

Publisher's Note Springer Nature remains neutral with regard to jurisdictional claims in published maps and institutional affiliations. 